\title{
PEMIKIRAN HERMENEUTIKA RUDOLF BULTMANN: EKSISTENSIALISASI DAN DEMITOLOGISASI
}

\author{
Nur Shofa Ulfiyati \\ Sekolah Tinggi Agama Islam (STAI) Al-Yasini Pasuruan, Indonesia \\ Email: shofaulfiyati@gmail.com
}

\begin{abstract}
Myth is an expression of a certain understanding of human existence. Sometimes mythology is often regarded as a primitive science or knowledge, which aims to explain the symptoms and events that are rare, strange or surprising and which people consider to be the result of evil spirits. This paper describes the existence of myths in the scriptures which should not be discarded, but rather given an explanation so that it can be understood for the present through the concept of Demitologization. Demythologization is the interpretation of parts of the Bible that are considered mythological by emphasizing the existential truths contained in the myth. According to Bultman, modern humans find it difficult to understand the preaching of the new agreement. In this case, Rudolf Bultmann as a theologian tried to think seriously about how a holy book from the pre-Muslim era could be accepted by modern humans so that he offered a demythologizing concept so that humans could believe what was in the scriptures.
\end{abstract}

Keywords: Rudolf Bultmann, Hermeneutics and Demythologizing

\begin{abstract}
Abstrak: Mitos adalah ekspresi dari suatu pemahaman yang tertentu tentang eksistensi manusia. Terkadang mitologi sering dianggap sebagai ilmu atau pengetahuan primitif, yang bermaksud untuk menjelaskan gejala-gejala dan kejadian-kejadian yang langka, yang asing atau yang mengejutkan dan yang dianggap orang sebagai akibat dari roh-roh jahat. Makalah ini menguraikan tentang bentuk eksistensi mitos dalam kitab suci yang mana semua itu tidak boleh dibuang, melainkan diberikan penjelasan sehingga dapat dipahami untuk masa kini melalui konsep Demitologisasi. Demitologisasi adalah tafsiran terhadap bagian-bagian Alkitab yang dianggap mitologis dengan menekankan kebenaran-kebenaran eksistensial yang terkandung dalam mitos itu. Menurut Bultman, manusia modern menemukan kesulitan untuk mengerti pemberitaan perjanjian baru. Dalam hal ini, Rudolf Bultmann sebagai seorang teolog berusaha memikirkan secara serius bagaimana sebuah kitab suci dari zaman prailmiyah dapat diterima oleh manusia modern sehingga ia menawarkan suatu konsep demitologisasi agar manusia dapat percaya apa yang ada dalam kitab suci.
\end{abstract}

Kata Kunci: Rudolf Bultmann, Hermeneutika, dan Demitologisasi 


\section{Pendahuluan}

Manusia selama berabad-abad lamanya hingga saat ini masih tetap mempercayai tentang mukjizat-mukjizat yang diberikan Tuhan kepada para NabiNya. Mukjizat tersebut sebagai bukti bentuk eksistensi Nabi sebagai wakil Tuhan sehingga Nabi bertindak sebagai penyelamat manusia dan membimbing manusia kepada jalan yang benar. Namun seiring berjalannya waktu manusia mengalami banyak perubahan, sebab dunia modern saat ini tentu manusia telah berfikir secara rasional sehingga jika ada hal-hal yang sifatnya irrasional sulit untuk diterima.

Pengetahuan manusia di bidang ilmu pengetahuan dan teknologi mengalami banyak perkembangan dan peningkatan, bagi manusia modern yang telah mengenal dan menggunakan alat-alat dari hasil ilmu pengetahuan dan teknologi tentu tidak mempercayai adanya mukjizatmukjizat yang mana hal tersebut dianggap bertentangan dengan hukum alam. Dalam hal ini pula, Rudolf Bultmann sebagai seorang teolog berusaha memikirkan secara serius bagaimana sebuah kitab suci dari zaman prailmiyah dapat diterima oleh manusia modern sehingga ia menawarkan suatu konsep demitologisasi agar manusia dapat percaya apa yang ada dalam kitab suci.

Dalam hal ini mitos adalah ekspresi dari suatu pemahaman yang tertentu tentang eksistensi manusia. Terkadang mitologi sering dianggap sebagai ilmu atau pengetahuan primitif, yang bermaksud untuk menjelaskan gejala-gejala dan kejadian-kejadian yang langka, yang asing atau yang mengejutkan dan yang dianggap orang sebagai akibat dari roh-roh jahat. Tetapi mitologi lebih daripada itu. Mitos berkata tentang dewa-dewa dan roh-roh jahat sebagai kuasa-kuasa yang padanya manusia bergantung. Konsep surga dan neraka (surga = di atas; neraka $=$ di bawah) yang dianggap oleh beberapa tokoh modern abad 20 -an adalah mitos yang dapat menjadi pertentangan bagi umat kristen. Pemikiran ini seolah-olah mengatakan bahwa Allah yang bertahtah di kerajan surga yang berada sangat jauh di atas bumi. Karena di atas bumi adalah dunia dari bintangbintang dan dari terang, yang membuat hidup manusia bercahaya dan bahagia ${ }^{1}$.

Bultmann sangat serius memikirkan bagaimana Injil yang dari zaman prailmiah dapat diberikan kepada manusia modern. Ia merasa terpanggil untuk menemukan suatu cara baru agar Injil boleh menyapa dan membuat manusia modern mengambil keputusan pribadi terhadap berita Injil. Pemikiran inovatif Bultmann ini tentu saja berkatian erat dengan Metode Kritik Bentuk-nya terhadap Perjanjian Baru. Melalui metode itu Bultmann mencoba menelusuri perkembangan lebih awal dari kisah-kisah Injil dalam penurunannya dan fungsinya dalam gereja purba. Ia mau menentukan kehistorisan kisah-kisah itu. Lalu ia sampai pada kesimpulan bahwa kebanyakan ucapan Yesus tidak berasal dari Yesus sendiri tetapi hasil redaksi dari jemaat purba. Selanjutnya, Bultmann juga tidak mengakui Alkitab sebagai firman Allah yang telah diwahyukan. Menurutnya, meskipun Allah berbicara kepada manusia melalui Alkitab, namun Alkitab itu merupakan hasil pengaruh sejarah dari agama kuno dan harus diadili seperti literatur religius kuno lainnya. Prinsip Kritik Bentuk. Bultmann ialah 'merombak' Injil dan kemudian mencoba menemukan bentuk asli dari Inji itu, lalu sedapat mungkin disusun kembali².

\section{Biografi Singkat Kehidupan Rudolf Bultmann}

Pada Tahun 1884 tepatnya tanggal 20 Agustus Rudolf karl Bultmann dilahirkan di Wiefelstede Jerman. Pernikahannya dengan Helene Feldmann dan dikaruniai tiga orang putri. Sebagai seorang teolog besar abad 20 Bultmann dikenal luas karena mencetuskan ide demitologisasi Perjanjian Baru sehingga Injil Kresten dapat dimungkinkan dipisahkan dari symbol-simbol mitologis. Di Universitas Marburg dia belajar di bawah bimbingan Wilhelm Herman yang teologinya menjadi dasar dari seluruh pemikiran teologi Bultmann. Ia memilih bidang Perjanjian Baru karena

\footnotetext{
${ }^{1}$ https://claus08192222454.wordpress.com/2010/01/15/rudolf-bultman-pit/diakses, tgl 09 desember 2017.

2 http://samuelwau.blogspot.co.id/2008/11/telaah-kritis-terhadap-demitologisasi.html, diakses tgl 09 Desember 2017.
}

30 Nur Shofa Ulfiyati - Pemikiran Hermeneutika Rudolf Bultmann: Eksistensialisasi dan Demitologisasi 
terpengaruh oleh Johannes Weiss yang juga berasal dari Universitas Marburg. Pada tahun 1908 Rudolf Bultmann menjadi guru besar di Marburg, dimana dia berkenalan dengan Wilhelm Heitmuller yang mendorongnya untuk melakukan spesialisasi di bidang History of Religions School. Secara khusus, ia kemudian mempelajari tiulisan-tulisan dari Perjanjian Baru kemudian diperbandingkan dengan catatan-catatan tentang agama-agama yang ada pada zaman gereja mulamula, antara lain dengan Hellenistic Gnosticism, Jewish Apokalyptic, dan agama-agama rahasia atau mystery religions. Pada tahun 1916 ia diangkat menjadi guru besar luar biasa di Breslau. Empat tahun kemudian, tahun 1920, ia pindah ke Giessen sebagai pengganti Professor Wilhelm Bousset dan pada tahun 1921 ia pindah ke Marburg sebagai guru besar di bidang Perjanjian Baru dan Sejarah Agama Kristen Kuno ${ }^{3}$. Bultmann meninggal-dunia pada tahun 1976.

Kuliahnya tentang Perjanjian Baru dan Mitologi: Masalah Demitologisasi terhadap Pesan Perjanjian Baru, menganjurkan para penafsir untuk menggantikan teologi yang tradisional dengan filsafat eksistensial dari kolega Bultmann, Martin Heidegger, sebuah upaya untuk membuat realitas ajaran-ajaran Yesus lebih dapat dipahami oleh para pembaca modern yang terdidik. Bultmann tetap yakin bahwa kisah-kisah kehidupan Yesus menawarkan teologi dalam bentuk cerita. Pelajaran-pelajaran diajarkan dalam bahasa mitos yang dikenal pada waktu itu. Semua itu tidak boleh dibuang, melainkan diberikan penjelasan sehingga mereka dapat dipahami untuk masa kini. Bultmann menganggap iman harus menjadi suatu realitas masa kini. Bagi Bultmann, manusia di dunia tampaknya selalu berada di dalam kekecewaan dan kegalauan. Iman harus menjadi suatu tindakan kehendak yang vital dan teguh, bukan upaya mengumpulkan dan mengagung-agungkan "bukti-bukti kuno". 4

Karya Bultmann dalam bidang teologi sangat berpengaruh dan mendapat banyak perhatian para ahli di bidangnya dan cukup produktif ditunjukkan dengan banyaknya karya yang ia tulis. Diantara karya buku teologi khususnya terkait tentang penafsiran Perjanjian Baru adalah The New Testament and Mythology, Theology of the New Testament, History and Eschatology: The Presence of Eternity, History of The Synoptic Tradition, Jesus Christ and Mythology, dan Religion without Myth ditulis bersama Karl Jaspers.

Kemampuan khusus yang dimiliki Bultmann di bidang Perjanjian Baru inilah yang membuat ia menjadi seorang sarjana teolog berpengaruh di abad 20, selain itu ia juga dikenal sebagai filsuf, ahli bahasa dan seorang ahli sejarah. Seorang filsuf yang mempengaruhi pemikiran filsafat Bultmann adalah Martin Heidegger yang dikenal dengan filsafat eksistensialisnya, mereka berdua berteman sejak tahun 1923 sampai 1928 sehingga dari pertemanan tersebut cukup mewarnai teologi Bultmann.

\section{Pemikiran Hermeneutika Bultmann: Eksistensialisasi dan Demitologisasi}

Secara etimologi, eksistensialisme berasal dari kata "eksistensi" dan dari kata eks yang berarti keluar dan sistensi yang diturunkan dari kata kerja sisto berarti berdiri. Eksistensialisme sendiri adalah gerakan filsafat yang menentang esensialisme, pusat perhatiannya adalah situasi manusia ${ }^{5}$. Dengan demikian eksistensi berarti manusia berdiri sebagai diri sendiri yang sadar bahwa dirinya ada, sehingga dengan begitu manusia secara individual menjadi sadar bahwa dia ada dan bebas. Kebalikan dari eksistensi adalah esensi. Esensi adalah yang menjadikan sesuatu benda apa adanya, atau sesuatu yang dimiliki secara umum oleh bermacam-macam benda. Esensi adalah umum untuk beberapa individu dan esensi dapat dibicarakan secara berarti walaupun tak ada contoh bendanya pada suatu waktu. Ciri umum dari eksistensialisme adalah eksistensi mendahului esensi ${ }^{6}$.

\footnotetext{
${ }^{3}$ M. Darojat Ariyanto, "RUdOLF BULTMANN: Demitologisasi dalam Perjanjian Baru," Jurnal Subuf 20 (2008), 178.

${ }^{4}$ https://id.wikipedia.org/wiki/Rudolf_Bultmann, diakses tgl 10 Desember 2017.

${ }^{5}$ Lorens Bagus, Kamus Filsafat (Jakarta: Gramedia Pustaka Utama, 2005), 185.

${ }^{6}$ Chafid Wahyudi, “Tuhan Dalam Perdebatan Eksistensialisme,” Jurnal Teosofi 02 (2002), 374.
} 
Demitologisasi adalah tafsiran terhadap bagian-bagian Alkitab yang dianggap mitologis dengan menekankan kebenaran-kebenaran eksistensial yang terkandung dalam mitos itu. Menurut Bultman, manusia modern menemukan kesulitan untuk mengerti pemberitaan perjanjian baru. Perjanjian baru mempunyai pandangan dunia yang sama sekali berbeda dengan pandangan modern tentang dunia (manusia abad 19-20). Manusia modern tidak dapat menerima lagi bahwa realitas ini dibagi atas 3 bagian, alam atas (surga), alam tengah (bumi tempat manusia dan tempat pertemuan kekuasaan ilahi dan demonis), alam bawah (neraka). Manusia modern tidak percaya kepada roh-roh dan kuasa-kuasa yang penuh kekuatan lagi. Manusia tidak percaya lagi akan mitos-mitos yang demikian?

Eksistensialisme adalah paham yang bertolak dari keberadaan manusia. Menurut Bultmann iman berarti "pembukaan diri kita secara bebas terhadap masa depan". Iman merupakan "tindakan penyerahan diri untuk memikul tanggung jawab secara taat, sekaligus suatu rasa bebas tak berpengaruh secara batiniah oleh dunia". Rupanya pernyataan-pernyataan mitologis yang objektif telah menjadi pernyataan eksistensialis mengenai manusia. Bultmann sendiri telah mengakui menggantikan teologi dengan antropologi, menafsirkan pernyataan mengenai Allah sebagai pernyataan mengenai kehidupan manusia. "maka jelaslah bahwa kalau manusia mau berbicara tentang Allah, ia harus berbicara mengenai diriny a sendiri". ${ }^{8}$

Menurut Bultmann Mukjizat tidak merupakan unsur yang penting dalam agama Kristen, tetapi hanya merupakan Unsur kebudayaan kulitnya saja, dan bukan unsur yang pokok. Maka, pendapat Bultmann lebih keras,: kalau orang Kristen masih menganggap dunia adikodrati bisa campurtangan dari dunia ini, kalau gitu Tuhan masih dianggap sebagai saingan manusia, maka pemikiran Tuhan Jauh dari sempurna. Kepercayaan terhadap mukjizat menghindarkan kita untuk mencapai konsep Tuhan yang sebenarnya. Tuhan mustahil merupakan objek yang bisa dilihat dalam dunia ini, dan percaya kepada mukjizat merupakan mengobjekkan penguasa adikodrati ini. Oleh karena itu ceritera tentang mukjizat harus diberi pengertian yang subjektif saja. Pada hari paskah mungkin atau malah tidak terjadi apapun dengan mayat Yesus, tetapi terjadi perubahan yang besar dalam jiwa murid. Sebelumnya, mereka kecewa dengan hukuman dan penyaliban Yesus, dan mereka takut aksi polisi Yahudi akan di teruskan sehingga kemudian mereka juga akan ditahan. Pada hari paskah, tidak terjadi kebangkitan Yesus tetapi kebangkitan semangat para murid Yesus, mereka menyadari, bahwa kabar baik dari Yesus tetap berlaku dan tidak hilang bersama dengan meninggalnya Yesus? .

Ada beberapa bahan dan materi yang digunakan Bultmann untuk menyusun teologinya berupa: (1) Kritik historis dari teologi liberal, (2) pengarahan kepada firman dan iman di dalam teologi dialektis, (3) ajaran reformatoris tentang pembenaran, (4) filsafat eksistensi Martin Heidegger. Dalam metode Bultmann merupakan pengaplikasian pikiran-pikiran eksistensial brillian Dasein (substansi dan temporalitas) Heidegger. Semuanya dimasak dalam dapur "Being and Time" secara konsekuen dan sistematis menjadi sesuatu yang baru dan memiliki cirinya sendiri. Tujuannya adalah sebagai pemberi arah pada soal percaya (glauben) dan mengerti (verstehen). Hal ini berarti bahwa Bultmann masih mendasarkan teologinya pada teologi dialektis, meskipun di sisi lain ia juga mengembangkan teologi liberal pada pemikiran historis kritis ${ }^{10}$.

Hermeneutika adalah ilmu yang mencoba menggambarkan bagaimana sebuah kata atau satu kejadian dalam waktu dan budaya lampau dapat dimengerti dan menjadi bermakna secara eksistensial dalam konteks situasi sekarang. Proses ini, ujar Braaten, melibatkan aturan metodologis yang diterapkan dalam penafsiran maupun asumsi-asumsi epistemologis tentang

\footnotetext{
${ }^{7}$ https://claus08192222454.wordpress.com/2010/01/15/rudolf-bultman-pit/, diakses tgl 11 Desember 2017.

${ }^{8} \mathrm{Ibid}$

${ }^{9}$ https:/ / fadlijafar.wordpress.com/2012/04/12/aliran-kristen-liberal-dalam-pemikiran-rudolf-bultmann/, diakses tgl 11 Desember 2017.

10 http://dangkalilmu.blogspot.co.id/2015/05/pemikiran-hermeneutika-rudolf-karl.html, Diakses tgl 11 Desember 2017.
}

32 Nur Shofa Ulfiyati - Pemikiran Hermeneutika Rudolf Bultmann: Eksistensialisasi dan Demitologisasi 
pemahaman. Sementara Rudolf Bultman sebagaimana dikutip dalam tulisan Abdul Moqsith Ghazalli, menyatakan the term hermeneutics is generally used to discrible the attempt to span the gap between past and present. Yang bermaksud, biasanya hermeneutika dipakai untuk menjembatani jurang antara masa lalu dan masa kini ${ }^{11}$. Tugas pokok hermeneutika adalah bagaimana menafsirkan sebuah teks klasik atau realitas sosial di masa lampau yang asing sama sekali menjadi milik orang yang hidup di masa, tempat dan suasana cultural yang berbeda. Dengan kata lain, hermeneutika selalu bergumul dengan persoalan pemahaman terhadap teks dalam pengertian luas, termasuk peristiwa sejarah, simbol-simbol maupun mitos ${ }^{12}$.

Dalam pandangan hermeneutika, dunia kehidupan sosial bukan hanya dunia yang dihayati individu-individu dalam masyarakat, tetapi juga merupakan objek penafsiran yang muncul karena penghayatan itu. Dengan demikian, dalam kaitannya dengan ilmu-ilmu sosial, hermeneutika merupakan penafsiran atau pemahaman atas dunia kehidupan tersebut. Oleh karena itu, sebagai metode pemahaman atas pemahaman (understanding of understanding), hermeneutika sangat sesuai diterapkan untuk ilmu-ilmu kemanusiaan (geitenwissenschaften) yang objeknya adalah ekspresi kehidupan (lebensaeusserung) meliputi konsep, tindakan dan penghayatan (erlebnis) manusia ${ }^{13}$.

Pusat dari konsep demitologisasi adalah pendirian Bultmann yang menemukan dua hal di dalam Perjanjian Baru, yaitu: a) Injil Kristen, dan b) pandangan orang pada abad pertama yang bercirikan mitos. Hakekat Injil, oleh Bultmann disebut dengan kerugma (Yunani $=$ isi yang dikhotbahkan), merupakan inti yang tidak dapat dipersempit lagi. Orang jaman modern ini harus dihadapkan dengan inti tersebut dan harus mempercayainya. Namun orang modern tidak dapat menerima kerangka yang bersifat mitos yang membungkus hakekat Injil. Oleh karena itu teologia harus berusaha untuk melepaskan berita kerugma dari kerangka yang bersifat mitos. Menurutnya kerangka yang bersifat mitos tidak selalu berkaitan dengan Kekristenan ${ }^{14}$.

Sehubungan dengan historitas Yesus, para teolog juga menilai bahwa apa yang tertulis dalam Injil tentang penggambaran pribadi Yesus telah tercemar oleh distorsi filosofis penulis Injil, yang tentu saja dipengaruhi oleh pemikiran mitologis tadi. Bertolak dari asumsi demikian, mereka mencoba mengemukakan beberapa alternative dalam rangka menghasilkan sebuah Kristologi yang sesuai dengan zaman Modern. Adapun metode pencarian yang di berlakukan oleh para teolog tadi adalah berdasarkan metode historis kritis ${ }^{15}$.

Dalam memahami teks ajaran Islam, para mufassirpun juga tidak boleh terjebak dalam hal-hal yang bersifat mitos. Maksudnya dalam hal ini makna demitologi eksistensial Islam rahmat li alálamîn menggunakan metode analisis historis kritis Bultmann. Dengan model analisis ini, Islam sebagai rahmat li al-álamîn bukan mitos yang hanya didengung-dengungkan oleh teks ajaran Islam, atau hanya diceramahkan, tetapi benar-benar terealisasi dalam praktik nyata untuk dunia ${ }^{16}$.

Menurut Arkoun mitos berperan sebagai layaknya fungsi agama; namun, tidak menggantikan agama itu sendiri. Dikatakan demikian karena mitos adalah impian-impian kebajikan universal yang berperan sebagai sumber nilai yang bisa dijadikan pedoman bagi kehidupan mereka. Sementara konsepsi-konsepsi agama yang tertuang dalam teks suci juga selalu memuat impianimpian ideal yang indah itu. Impian-impian indah itu misalnya tentang gambaran indahnya surga, yang di bawahnya mengalir air sungai, di dalamnya terdapat rizki atau buah-buah serta istri-istri yang suci (bidadari). Perbedaan keduanya hanya terletak pada subjek yang melakukan konstruksi

\footnotetext{
11 http://library.walisongo.ac.id/digilib/files/disk1/26/jtptiain-gdl-s1-2006-wiwitrizka-1291-bab2_210-7.pdf, diakses tgl 11 Desember 2017

12 Ilyas Supena, "Epistemologi Hukum Islam dalam Pandangan Hermeneutika Fazlurrahman,” Jurnal Asy-Syir'ah 42 (2008), 248.

${ }^{13}$ Ilyas Supena, "Hermeneutika Kritis Jürgen Habermas (Implikasinya bagi Pengembangan Ilmu-Ilmu Keislaman)," Jurnal Teologia 16 (2005), 6.

${ }^{14}$ M. Darojat Ariyanto, ” Teologi Kristen Modern Di Eropa,” Jurnal Subuf 22 (2010), 169.

15 Muslihah, "Yesus yang Historis dalam Teologi Rudolf Bultmann," Skripsi UIN SUKA (2001), 4.

16 Sokhi Huda, "Pemikiran dan Praksis Dakwah Sufistik M. Fethullah Gulen," Jurnal Islamica 11 (2017), 316-317.
} 
atas impian ideal itu. Subjek konstruksi mitos adalah manusia, sedangkan subjek konstruksi agama adalah dua kekuatan kompromistik antara Tuhan sebagai representasi wahyunya dan manusia sebagai representasi hasil penafsirannya. Dalam kondisi seperti ini, manusia tidak akan mampu hidup tanpa agama, demikian juga tanpa mitos, sekalipun ia selalu mengalami perubahan dari zaman ke zaman dan dari generasi ke generasi ${ }^{17}$. Mitos dalam kaitannya dengan agama menjadi penting bukan sematamata karena memuat hal-hal gaib atau peristiwa-peristiwa mengenai makhluk adikodrati, melainkan karena mitos tersebut memiliki fungsi eksistensial bagi manusia dan karenanya mitos harus dijelaskan menurut fungsinya ${ }^{18}$.

Begitu pula dalam kajian Hadis Nabi harus dapat dipahami melalui pendekatan sirah (sejarah) sehingga hal tersebut menjadi sangat penting. Melalui kajian Sirah ini maka tentu dapat diketahui dengan jelas psikologi Nabi sebagai manusia biasa. Dengan sirah, hadis dapat dipahami dengan tepat dan akurat. Dengan sirah, dapat diketahui mana tindak tutur Nabi yang bersumber dari budaya, dan mana yang berasal dari wahyu. Melalui sirah, kehidupan nabi dapat dicitrakan sebagai apa adanya, tanpa ada unsur mitologisasi, pengkultusan, atau penghinaan. Dengan demikian, sirah adalah sebuah pendekatan yang tepat untuk demitologisasi kehidupan Nabi saw ${ }^{19}$.

\section{Kesimpulan}

Bagi manusia modern yang telah mengenal dan menggunakan alat-alat dari hasil ilmu pengetahuan dan teknologi tentu tidak mempercayai adanya mukjizat-mukjizat yang mana hal tersebut dianggap bertentangan dengan hukum alam. Dalam hal ini pula, Rudolf Bultmann sebagai seorang teolog berusaha memikirkan secara serius bagaimana sebuah kitab suci dari zaman prailmiyah dapat diterima oleh manusia modern sehingga ia menawarkan suatu konsep demitologisasi agar manusia dapat percaya apa yang ada dalam kitab suci. Menurut Bultmann kalau orang Kristen masih menganggap dunia adikodrati bisa campurtangan dari dunia ini, kalau gitu Tuhan masih dianggap sebagai saingan manusia, maka pemikiran Tuhan Jauh dari sempurna. Kepercayaan terhadap mukjizat menghindarkan kita untuk mencapai konsep Tuhan yang sebenarnya. Tuhan mustahil merupakan objek yang bisa dilihat dalam dunia ini, dan percaya kepada mukjizat merupakan mengobjekkan penguasa adikodrati ini. Oleh karena itu ceritera tentang mukjizat harus diberi pengertian yang subjektif saja.

\footnotetext{
${ }^{17}$ Roibin, “Agama dan Mitos:Dari Imajinasi Kreatif Menuju Realitas Yang Dinamis," Jurnal el-Harakah 12 (2010), 86 87.

18 Ibid.

19 Ahmad 'Ubaydi Hasbillah, "Sirah Nabawiyah dan Demitologisasi Kehidupan Nabi," Journal of Qur'an and Hadith Studies 1 (2012), 274.
} 


\section{Daftar Pustaka}

Ariyanto, M. Darojat" Teologi Kristen Modern Di Eropa,” Jurnal Subuf 22 (2010).

"RUDOLF BULTMANN: Demitologisasi dalam Perjanjian Baru," Jurnal Subuf 20 (2008).

Bagus, Lorens Kamus Filsafat Jakarta: Gramedia Pustaka Utama, (2005).

Hasbillah, Ahmad 'Ubaydi "Sirah Nabawiyah dan Demitologisasi Kehidupan Nabi," Journal of Qur'an and Hadith Studies 1 (2012).

Huda, Sokhi "Pemikiran dan Praksis Dakwah Sufistik M. Fethullah Gulen," Jurnal Islamica 11 (2017).

Muslihah, "Yesus yang Historis dalam Teologi Rudolf Bultmann," Skripsi UIN SUKA (2001).

Supena, Ilyas "Epistemologi Hukum Islam dalam Pandangan Hermeneutika Fazlurrahman," Jurnal Asy-Syir'ah 42 (2008).

"Hermeneutika Kritis Jürgen Habermas (Implikasinya bagi Pengembangan IlmuIlmu Keislaman)," Jurnal Teologia 16 (2005).

Roibin, “Agama dan Mitos:Dari Imajinasi Kreatif Menuju Realitas Yang Dinamis," Jurnal elHarakah 12 (2010).

Wahyudi, Chafid “ Tuhan Dalam Perdebatan Eksistensialisme,” Jurnal Teosofi 02 (2002).

https://claus08192222454.wordpress.com/2010/01/15/rudolf-bultman-pit/diakses, tgl 09 desember 2017.

http://samuelwau.blogspot.co.id/2008/11/telaah-kritis-terhadap-demitologisasi.html, diakses tgl 09 Desember 2017.

https://id.wikipedia.org/wiki/Rudolf_Bultmann, diakses tgl 10 Desember 2017.

https://claus08192222454.wordpress.com/2010/01/15/rudolf-bultman-pit/, diakses tgl 11 Desember 2017.

https:/ fadlijafar.wordpress.com/2012/04/12/aliran-kristen-liberal-dalam-pemikiran-rudolfbultmann/, diakses tgl 11 Desember 2017.

http://dangkalilmu.blogspot.co.id/2015/05/pemikiran-hermeneutika-rudolf-karl.html, Diakses tgl 11 Desember 2017.

http:/ /ibrary.walisongo.ac.id/digilib/files/disk1/26/jtptiain-gdl-s1-2006-wiwitrizka-1291bab2_210-7.pdf, diakses tgl 11 Desember 2017. 